\title{
Chronic Lymphocytic Leukemia- Modified Rai Staging System
}

National Cancer Institute

\section{Source}

National Cancer Institute. Chronic Lymphocytic Leukemia-Modified Rai Staging System. NCI Thesaurus. Code C141206.

A term that refers to the staging of chronic lymphocytic leukemia according to modified Rai staging system. This system is mainly used in North America. 